Original Article

Dr. Suraj Thulung, MS, MCH

Consultant Neurosurgeon

Dr. Suresh Bishokarma, MS

$\mathrm{MCH}$ Neurosurgery resident

Dr. Subash Lohani, MS

MCH Neurosurgery resident

Dr. Dinuj Shrestha, MBBS

FCPS Neurosurgery Resident

Dr. Binit Aryal, MBBS

Medical officer

Dr. Munu Napit, MBBS

Medical officer

Department of Neurosurgery

Upendra Devkota Memorial National Institute of Neuro-

logical and Allied Science

Address for correspondence:

Dr Suraj Thulung

Consultant Neurosurgeon

Department of Neurosurgery,

Upendra Devkota Memorial National Institute of Neuro-

logical and Allied Sciences

Bansbari, Kathmandu Nepal;

P. O. Box: 3711; Fax: +977-1-4370779

Email: surajthulung@yahoo.com;

Mobile: +977-9851154356

Date submitted : 11/3/2019

Date accepted : 9/5/2019
Nepal Journal of Neurosciences 16:25-28, 2019

\section{Clinical Experience With Frameless Neuronavigation Guided Biopsy For Intracranial Space Occupying Lesion}

Biopsy is mandatory for histological diagnosis of non-resectable brain tumors. Of various techniques, neuronavigation guided biopsy provides intraoperative real-time reference and allows biopsy from multiple trajectories. The aim of this study is to assess the efficacy and accuracy of frameless neuronavigation biopsy.

We retrospectively reviewed the medical archives of patients with intracranial space occupying lesion who underwent frameless neuronavigation biopsy at our institute between 2016 to 2018. All operations were performed under general anesthesia. Data were analyzed by SPSS version 20. P value of $<0.05$ was considered significant.

There were 46 patients who underwent neuronavigation guided biopsy over the period of two years. Median age of patients was 46.5 years. Supratentorial tumors accounted for $95.8 \%$ of cases. Mean tumor diameter was 3.35 $\mathrm{cm}$. Accuracy was $89.1 \%$. More than half were glial tumors. Histopathology was inconclusive in $10.9 \%$ cases. Complication rate was $4.3 \%$ : one tract hematoma and one new neurological deficit.

Frameless neuronavigation guided biopsy of intracranial space occupying lesion is safe and efficacious procedure with high diagnostic yield.

Keywords: Biopsy, Frameless, Neuronavigation, Space occupying lesion

empirical therapy without histological verification is rarely indicated. ${ }^{12}$ Of the various technique, neuronavigation guided biopsy provides intraoperative real-time reference and it also allows us to perform multiple biopsy from multiple trajectories.1Neuronavigation guided frameless stereotactic biopsy (NSTB) by using magnetic resonance imaging (MRI) is also an accurate and less invasive method of diagnosis. ${ }^{5-7,12,13,16}$ There have been limited studies to gauze at the procedural efficacy and accuracy 
Thulung et al

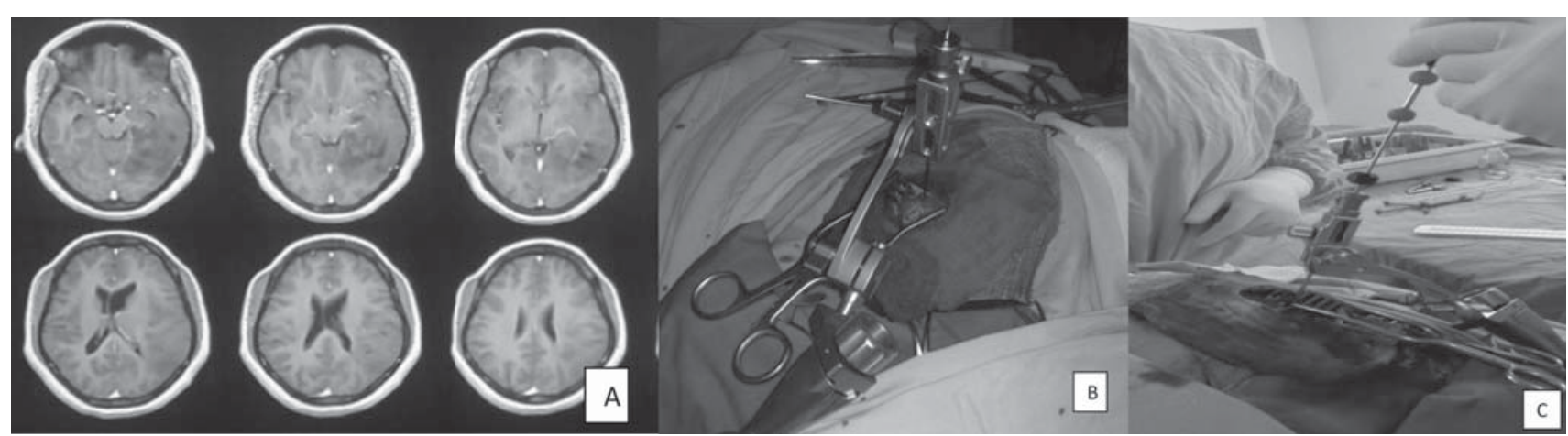

Figure 1: A: Pre-operative MRI; B: Neuronavigation biopsy technique- Target lesion is navigated and locked for biopsy from shortest safe route; $C$ : Delivering Biopsy specimen.

of neuronavigation technique. The aim of this study is to assess the efficacy and accuracy of frameless neuronavigation technique and analyze the characteristics of the pathology subjected to such technique.

\section{Materials and Methods:}

We retrospectively reviewed the medical archives of 46 patients with intracranial space occupying lesion who underwent frameless neuronavigation biopsy at our institute from 2016 to 2018. Biopsy for tissue diagnosis of lesions located in inaccessible locations were taken. Biopsies were also taken from patients who cannot withstand major surgical procedure irrespective of location of the lesions. Those cases were excluded where lesions were located in superficial and accessible locations with good Karnofsky scoring. In these circumstances, regular surgical procedures were performed; hence they were not included in our study. All operations were performed under general anesthesia. Data were analyzed by SPSS ver 20. Proportion and Mean were deduced for categorical data and continuous variables respectively. $\mathrm{P}$ value of $<0.05$ was considered significant

\section{Technique of Stealth neuronavigation frameless biopsy:}

Image acquisition was done from MRI image loaded compact disc and patient registered in Stealth, neuronavigation system, an infrared led based system. Head of patient was shaved after general anesthesia and head fixed with three pins clamp on Mayfield. Taylor Haughton line drawn and tumor marked on scalp with neuronavigation guidance. Entry point selection done to achieve shortest safe path toward target lesion (Figure 1B). All the calculations were done to avoid vascular structure along the trajectory. Skin incision done and burr hole created with manman air driven drill. Durotomy done and specimens were retrieved with the help of 14-gauge navigation cannula (Figure 1C). Biopsy specimens sent for histopathological analysis. Wound closed with one or two stitches and observed in intensive care unit for monitoring.

\section{Results:}

Out of 46 patients who underwent neuronavigation guided biopsy of intracranial space occupying lesion, most of them were male ( 30 patients) with male to female ratio of 1.15:1. Median age of patients was 46.5 years with range from 5 to 82 years. Supratentorial tumor accounted $95.8 \%$ (45 patients). Most tumors were observed in right side (56.5\%) while $41.3 \%$ tumors were in left side and $2.2 \%$ tumor being in midline (Pineal tumor). Lobar location was found in 24 patients $(52.2 \%)$ while 22 tumors (47.8\%) were in deep location. Most common location was frontal (23.9\%) followed by Thalamic (13\%)/Periventricular (13\%). Mean size of lesion was $3.35 \pm 0.92 \mathrm{cms}$ ranged from 2 to $7 \mathrm{~cm} .41$ patients had tumor size more than $2 \mathrm{~cm}$ while 6 patients had tumor size $\leq 2 \mathrm{cms}$. (Table 1 )

\begin{tabular}{|l|l|l|}
\hline Location of lesion & Frequency & Percent \\
\hline Frontal & 11 & 23.9 \\
\hline Parietal & 7 & 15.2 \\
\hline Periventricular & 6 & 13.0 \\
\hline Thalamic & 6 & 13.0 \\
\hline Multi focal & 4 & 8.7 \\
\hline Diffuse & 3 & 6.5 \\
\hline Temporal & 3 & 6.5 \\
\hline Occipital & 2 & 4.3 \\
\hline Callosal & 2 & 4.3 \\
\hline Cerebellar & 1 & 2.2 \\
\hline Pineal & 1 & 2.2 \\
\hline Total & 46 & 100.0 \\
\hline
\end{tabular}

Table 1: Location of lesion 


\section{Neuronavigation biopsy}

Biopsy was accurate to retrieve target in $89.1 \%$ (41 patients). (Table 2) Histopathology revealed glial tumor in $52.2 \%$ of cases. Out of 46 biopsies, 20 were Glioblastoma WHO Grade IV (43.5\%), 6 were Lymphoma (13\%), 5 were abscess $(10.9 \%)$ followed by few cases of diffuse astrocytoma, WHO Gr II, Anaplastic astrocytoma WHO grade III, tuberculoma, cryptococcal lesion etc. (Table 3)

\begin{tabular}{|c|c|c|}
\hline Histopathological diagnosis & Frequency & Percent \\
\hline \multicolumn{3}{|l|}{ TUMOR } \\
\hline Glioblastoma WHO Gr IV & 20 & 43.5 \\
\hline Lymphoma & 6 & 13.0 \\
\hline $\begin{array}{l}\text { Diffuse astrocytoma, WHO } \\
\text { Gr II }\end{array}$ & 2 & 4.3 \\
\hline $\begin{array}{l}\text { Anaplastic astrocytoma } \\
\text { WHO grade III }\end{array}$ & 2 & 4.3 \\
\hline Metastatic Adenocarcinoma & 1 & 2.2 \\
\hline $\begin{array}{l}\text { Metaplastic meningioma } \\
\text { Grade I }\end{array}$ & 1 & 2.2 \\
\hline $\begin{array}{l}\text { Pleomorphic Xanthoastrocy- } \\
\text { toma WHO II }\end{array}$ & 1 & 2.2 \\
\hline \multicolumn{3}{|l|}{ INFECTIVE } \\
\hline Abscess & 5 & 10.9 \\
\hline Tuberculoma & 2 & 4.3 \\
\hline Cryptococcal lesion & 1 & 2.2 \\
\hline Inconclusive & 5 & 10.9 \\
\hline Total & 46 & 100.0 \\
\hline
\end{tabular}

Table 2: Final diagnosis of brain biopsy via frameless neuronavigation technique

\begin{tabular}{|l|l|}
\hline \multicolumn{2}{|l|}{ Frameless neuronavigation biopsy } \\
\hline No. of Biopsy & 46 \\
\hline Positive & 41 \\
\hline Negative & $89.1 \%$ \\
\hline
\end{tabular}
biopsy

Table 3: Diagnostic yield of frameless neuronavigation

In five cases, HPE was inconclusive (10.9\%). Among the inconclusive diagnosis, Gliosis was reported in 3 cases and normal brain in 2 patients. (Table 4 )

\begin{tabular}{|l|c|}
\hline Negative reports & Frequency \\
\hline Gliosis & 3 \\
\hline Normal brain & 2 \\
\hline Total & 5 \\
\hline
\end{tabular}

Table 4: INCONCLUSIVE DIAGNOSIS $(N=5)$
With Neuronavigation technique, new diagnosis was revealed in $26.1 \%$ (12) patients while diagnosis was static to preoperative diagnosis in 63 patients $(29 \%)$. (Table 5)

\begin{tabular}{|l|l|l|}
\hline Change in diagnosis & Frequency & Percent \\
\hline Preoperative diagnosis static & 29 & 63.0 \\
\hline Diagnosis revised & 12 & 26.1 \\
\hline Inconclusive & 5 & 10.9 \\
\hline Total & 46 & 100.0 \\
\hline
\end{tabular}

Table 5: Alteration in preoperative diagnosis following neuronavigation biopsy

Overall morbidity was observed in $2(4.3 \%)$ patients, of which one patient had tract hematoma while another patient had seizure and both were managed conservatively. There is no procedure related mortality in this study during study period.

Post operatively, we decided further management based upon the histopathologic analysis. Patients with diagnosis of brain tumor were referred to neuro-oncologist for chemo-radiotherapy, infected cases were managed with intravenous antibiotics and some were operated for revision of diagnosis.

\section{Discussion}

Stereotactic biopsy of brain lesions has been a widely and safely performed procedure with high accuracy procedure since it was first introduced in the late 1970s., ${ }^{415}$ Literature comparing diagnostic yield of neuronavigation technique is sparse. Hence this study was undertaken to evaluate diagnostic yield of frameless neuronavigation.

The diagnostic accuracy of neuronavigation biopsy was reported from $87 \%$ to $97.6 \% .1,8$ in different literatures. In our study, diagnostic accuracy of frameless neuronavigation technique was $89.1 \%$. Among 46 patients, HPE revealed accurate diagnosis in 41 patients (89.1\%) and inconclusive among 5 patients (10.9\%). In a study done by Jain D et al.among 15 patients, conclusive diagnosis was made in 13 patients $(86.6 \%)$ while in a study done by Barnett et al. ${ }^{1,8}$ among 208 supratentorial lesion, diagnostic yield was $97.6 \%$ while Dorward et al.had diagnostic yield of $98.6 \%{ }^{6}$

Mean diameter of tumor in our study was $3.35 \pm 0.92$ $\mathrm{cm}$ and ranged from 2 to $7 \mathrm{~cm}$. In a study done by Dorward et al., the mean size of tumor was $3.87 \pm 1.9 \mathrm{~cm}$ with range from $0.7 \mathrm{~cm}$ to $10.2 \mathrm{~cm}$ among frameless biopsy group. ${ }^{6}$ Various literature suggested the volume of brain lesion influences the diagnostic yield. The larger the lesion, the greater the likelihood to result in diagnostic biopsy and vice versa. ${ }^{11,16}$ However, we didn't find any significant 


\section{Thulung et al}

difference in diagnostic yield among tumors $\leq 2 \mathrm{~cm}$ or $>2 \mathrm{~cm}$ size.

In our study, histopathology revealed glial tumor in $52.2 \%$ of cases. Out of 46 biopsies, 20 were Glioblastoma WHO Grade IV (43.5\%), 6 were Lymphoma (13\%), 5 were abscess $(10.9 \%)$ followed by few cases of diffuse astrocytoma WHO Grade II, Anaplastic astrocytoma WHO grade III, Tuberculoma and Cryptococcal lesion. In a study done by Tsermoulas $\mathrm{G}$ et al. among 124 patients, diagnostic accuracy of $93.5 \%$ with Glioblastoma was most common (41.12\%) followed by B cell lymphoma (17.74\%) which was comparable to our study.14 Among inconclusive report, 2 were normal brain and 2 were gliosis. Reason for negative report was due to missed target acquiring normal brain for histology or retrieval of glial tissue/nonspecific chronic inflammatory tissue from target. In our study, there were $26 \%$ new cases diagnosed with neuronavigation guided biopsy. Study done by Jain D et al. had overall negative result in 16\% (21 patients out of 130) cases. ${ }^{8}$ Histological analysis showed normal brain in $8.5 \%$, gliosis in $3 \%$ and inadequate tissue in $3 \%$ cases. $^{8}$

The overall morbidity of needle biopsy is reported from $0.9 \%$ to $15 \%$ in different literature. ${ }^{2,9}$ In our study, overall morbidity was observed in $2(4.3 \%)$ patients. Kreth et al. highlighted hematoma related complication as a common. ${ }^{9}$ Most common complication following needle biopsy was reported to be hemorrhage. ${ }^{10}$ We had one case of tract hematoma in our series which was managed conservatively.

Conclusion: Neuronavigation guided biopsy of intracranial space occupying lesion is safe and efficacious procedure with high diagnostic yield. This study has limitations of being a retrospective study. We recommend future prospective study to compare neuronavigation technique with other needle biopsy technique to ascertain the accuracy and efficacy of the neuronavigation technique.

\section{References}

1. Barnett GH, Miller DW, Weisenberger J. Frameless stereotaxy with scalp-applied fiducial markers for brain biopsy procedures: experience in 218 cases. Journal of Neurosurgery 91:569-576, 1999

2. Bernstein M, Parrent AG. Complications of CTguided stereotactic biopsy of intra-axial brain lesions. Journal of Neurosurgery 81:165-168, 1994

3. Chen SY, Chen CH, Sun MH. Stereotactic biopsy for brainstem lesion: Comparison of approaches and reports of 10 cases. Journal of the Chinese Medical Association 74:110-114, 2011

4. Conway LW. Stereotaxic diagnosis and treatment of intracranial tumors including an initial experience with cryosurgery for pinealomas. Journal of Neurosurgery 38:453-460:1973
5. Dammers R, Haitsma IK, Schouten JW, kros JM, Avezaat CJ, Vincent AJ. Safety and efficacy of frameless and frame-based intracranial biopsy techniques. Acta Neurochirurgica 150:23-29, 2008

6. Dorward NL, Paleologos TS, Alberti O. The advantages of frameless stereotactic biopsy over frame-based biopsy. British Journal of Neurosurgery 16:110-118, 2002

7. GrallaJ, Nimsky C, Buchfelder M. Frameless Stereotactic Brain Biopsy Procedures Using the Stealth Station: Indications, Accuracy and Results. Zentralblatt Fur Neurochirurgie 64:166-170, 2003

8. Jain D, Sharma MC, Sarkar C, Deb P, Gupta D, Mahapatra AK. Correlation of diagnostic yield of stereotactic brain biopsy with number of biopsy bits and site of the lesion. Brain Tumor Pathology 23:71-75, 2006

9. Kreth FW, Muacevic A, Medele R, Bise K, Meyer T, Reulen HJ. The risk of haemorrhage after image guided stereotactic biopsy of intra-axial brain tumours- a prospective study. Acta Neurochirurgica 143: 539-545, 2001

10. Krieger MD, Chandrasoma PT, Zee CS, Apuzzo ML. Role of stereotactic biopsy in the diagnosis and management of brain tumors. Seminars in Surgical Oncology 14:13-25, 1998

11. Lee T, Kenny BG, Hitchock ER. Supratentorial masses: stereotactic or freehand biopsy? British Journal of Neurosurgery 5:331-338, 1991

12. McGirt MJ, Woodworth GF, Coon AL, Frazier JM, Garonzik I, Olivi A. Independent predictors of morbidity after image-guided stereotactic brain biopsy: a risk assessment of 270 cases. Journal of Neurosurgery 102:897-901, 2005

13. Paleologos TS, Dorward NL, Wadley JP, Thomas DG. Clinical validation of true frameless stereotactic biopsy: analysis of the first 125 consecutive cases. Neurosurgery 49:830-835, 2001

14. Tsermoulas G, Mukerji N, Borah AJ, Mitchell P, Ross N. Factors affecting diagnostic yield in needle biopsy for brain lesions. British Journal of Neurosurgery 27:207-211, 2013

15. WidmannG, Schullian $\mathrm{P}$, Ortler $\mathrm{M}$, Bale R. Frameless stereotactic targeting devices: technical features, targeting errors and clinical results. The International Journal of Medical Robotics and Computer Assisted Surgery 8:1-16, 2012

16. Woodworth GF, McGirt MJ, Samdani A,Garonzik I, Olivi A, Weingart JD. Frameless image-guided stereotactic brain biopsy procedure: diagnostic yield, surgical morbidity, and comparison with the framebased technique. Journal of Neurosurgery 104:233237, 2006 